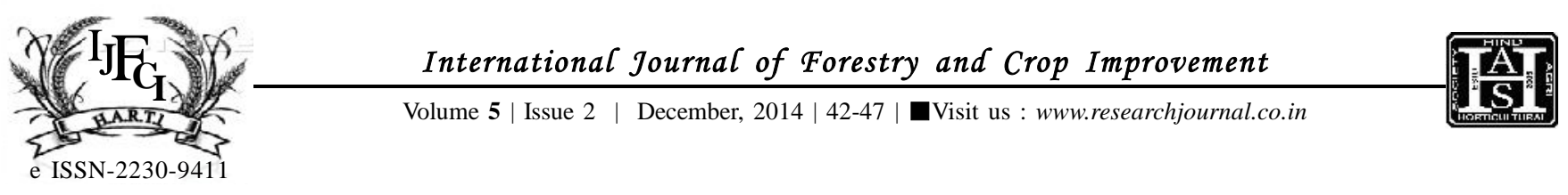

\title{
Microsymbiont enhances survival of teak seedlings and nutrient status of soils under saline soils
}

\author{
SwATI SHEdAGE AND N.S. PATIL
}

\begin{abstract}
Seedlings of teak were planted under different salinity levels viz., normal soil (<4 ECe soil), saline soil (4-8 Ece) and highly saline soil (8-12 ECe) and seedlings were inoculated with Azetobactor + vesicular-arbuscular mycorrhizal (VAM) fungi, Azospirillium + vesiculararbuscular mycorrhizal (VAM) fungi and combination of all three. Experiment repeated for two years and data recorded at the end of each experiment on nutrient satus of soil $\mathrm{pH}, \mathrm{ECe} \mathrm{N}, \mathrm{P}, \mathrm{K}, \mathrm{Ca}, \mathrm{Mg}, \mathrm{Na}$, micronutrient (Fe, $\mathrm{Zn}, \mathrm{Mn}$ and $\mathrm{Cu}$ ) and survival per cent of seedlings. Triple inoculation (Azetobactor+Azospirillium+VAM) significantly influenced on the nutrient status of soil and survival per cent of teak seedlings as compared to uninoculated seedlings under salt condition. Which was followed by dual inoculation of Azospirillium and VAM.
\end{abstract}

KEY WORDS : Microsymbiont, Salinity levels, Nutrient status of soil, Survival per cent

How to cite this Article : Shedage, Swati and Patil, N.S. (2014). Microsymbiont enhances survival of teak seedlings and nutrient status of soils under saline soils. Internat. J. Forestry \& Crop Improv., 5 (2) : 42-47.

Article Chronical : Received : 19.08.2014; Revised : 23.10.2014; Accepted : 10.11.2014 